\title{
VALORIZATION OF RARE EARTH ELEMENTS FROM END-OF-LIFE FLUORESCENT LAMPS: A CONTRIBUTION TO URBAN MINING
}

\author{
Alessandra Bonoli ${ }^{1, \star}$, Werther Boninsegni ${ }^{2}$ and Eleonora Foschi ${ }^{1}$ \\ ${ }^{1}$ Department of Civil, Chemical, Environmental and Materials Engineering, University of Bologna, via Terracini 28,40131 Bologna, \\ Italy \\ ${ }^{2}$ DISMECO SpA, Via Vittorio Peglion 2, 40128 Bologna, Italy
}
Article Info:
Received:
31 July 2020
Revised:
9 April 2021
Accepted:
12 April 2021
Available online:
6 June 2021
Keywords:
Rare Earth Elements
Urban Mining
Recycling
WEEE
Fluorescent lamps

\begin{abstract}
In recent decades, Rare Earth Elements (REEs) have assumedfundamental place in the electrical and electronic (EE) industry as a result of the increasing interest in low-energy and intelligent technologies. Availability of those elements in limited area of the globe, the complexity of extraction processes and the high costs of their valorization negatively influence the supply chain to such an extent as to jeopardize the future offer of EE equipment. This issue is particularly acute in Europe where all REEs are imported, particularly from China that has a dominant position in the global market. To contrast this dependence and ensure a stable future demand, industrial stakeholders have embarked on an ambitious path aimed at recovering REEs from EEE waste. Indeed, the promotion of policies and measures for a circular economy has identified in urban mining the way to address this challenge.Cities are considered as a reserve of minerals, although applied research is still in its infancy and currently only $1 \%$ of REEs is recovered. Whilst handling waste, fluorescent lamps proves mainly challenging due to the presence of hazardous substances; however, they yield the highest purity rare-earth oxides. This article represents a preliminary multi-criteria analysis aimed at assessing the feasibility of launching an urban mining project based on the valorization of REEs from fluorescent lamps. The work is the result of the activities undertaken by the Italian WEEE company DISMECO in collaboration with the University of Bologna, paving the way for a more profitable circular economy for REEs.
\end{abstract}

\section{INTRODUCTION}

The well-known impacts generated by the linear economy on the environment, the problems deriving from resource scarcity, and the increasing awareness of critical climate change-related issues, have nurtured the rethinking of production and consumption patterns by adopting green processes and products (Beamon, 1999; Wong, 2012; Gadimi et al, 2019). Recycling and secondary raw materials can massively contribute to reducing carbon emissions, and therefore, to ensure a sustainable value chain and promote a more circular economy model (Zorpas, 2016). In a life cycle perspective, the valorization of the intrinsic value of materials at the end-of-life (EoL) has been a key element for reducing the manufacturing industry's carbon footprint. The life-cycle assessment (LCA) studies recently performed by Ibanescu et al. (2018) on five European WEEE management systems reveal a net negative total carbon footprint, thus showing the significant contribution of recycling in the WEEE (Waste from Electrical and Electronic
Equipment) treatment options. Additionally, during the materials extraction and processing phase, recycling, and in particular upcycling, massively contributes to minimizing $\mathrm{CO}_{2}$ emissions thanks to the reduction of virgin materials (Lieder et al., 2017; Nascimento et al., 2019; Riesener et al., 2019; Clarke et al., 2019).

\subsection{The role of recycling in the EU high-tech industry}

Recycling assumes higher relevance in Europe, where the reserves of oil, metals, and resources in general, are insufficient to meet the local demand. The presence of the so-called Rare Earth Elements (REEs) is confined to the Finnish country, holding the Cobalt market while the French region is the leading Hafnium supplier (European Commission, 2018). All the other materials are basically imported. In particular, Europe is highly dependent on China for the supply of "high-tech" metals such as Cobalt, Platinum, Rare Earths, and Titanium. Moreover, a residual business is controlled by the USA (especially for Beryllium and Helium) and Russia, which contains the business transactions 
for Cobalt and Scandium's reserve (European Commission, 2018). The economic aspect is relevant in the electrical and electronic (EE) sector, which is characterized by massive use of Gold, Copper, Silver, Titanium and REEs. In 2016, the EE industry registered a world market share of $14,6 \%$ (Oladele et al., 2009; Li et al., 2015). The main applications include refrigerators, illumination devices, mobile phones, tv, computers, and general high-tech equipment. Nowadays, the growing interest in low-carbon (solar panels, wind turbines and batteries etc.) and smart technologies (internet of things, cloud manufacturing, advanced automation etc.) has affected the demand for these materials that are expected to increase by a factor of 20 by 2030 (European Commission, 2016). Although the EE market represents an opportunity for a more competitive Europe, issues related to REEs supply are severe, especially for Europium (Eu), Neodymium (Nd), Terbium (Tb), Dysprosium (Dy), and Yttrium (Y) (Binnemans et al., 2013).

To ensure the survival of the Information and Communication Technologies (ICT) sector, the European (EU) Commission launched the European Raw Materials Initiative aimed at identifying those materials that have already reached or exceed the natural stocks (Baccini and Brunner, 2012; Bakker, 2012). The reasons why these materials are particularly critical are:

- the significant economic importance for key emerging sectors

- the increasing demand that is not ensured by the local availability and therefore contributing to supply risks, price volatility, and strict dependence from importing countries

- the lack of valid alternatives from the economic and technical point of view.

According to the variables mentioned above, the list is continuously monitored and updated in the EU Raw Materials Information System (Bio by Deloitte, 2015). The last analysis performed by UNEP reveals that less than $1 \%$ of REEs are globally recycled (UNEP, 2011). In Europe, even if the collection rate of household WEEE amounted to 492,532 tonnes in 2018 , it was insufficient to meet the collection target established by the Directive 2012/19/EC entered into force on $13^{\text {th }}$ of August 2012. The directive introduced stepwise higher collection targets to be applied from 2016 and 2019 (European Commission, 2012).

Consequently, major efforts are needed to be competitive in the global market. The circular economy covers a pivotal role in fostering this transition. The Circular Economy action plan, published by the Commission in 2015 and updated in 2019, represents the key innovative legislation in this field. The circular economy roadmap contains, among the most urgent sectors of intervention, actions aimed at closing the loop of electronics, ICT, and batteries industries (European Parliament and of the Council, 2015). Indeed, the Directive 2018/849/EC (2018b) broadens product types that fall in the compliance scheme and follows a separate collection process and special treatment.

\subsection{Urban mining: an opportunity for a flourishing market of REEs in Europe}

Among the circular strategies, recycling is the most exploited waste treatment (Price, 2000). While material valorization is well-established in some value chains such as plastics, glass and paper, the recycling of precious metals and REEs is still an embryonic process due to small contents and the difficulties in the extraction and the separation processes (Fellner et al., 2017). Problems are also related to the mis-collection of EE waste. To highlight the importance of monitoring and extracting value from materials in urban areas, the concept of urban mining has been introduced (Krook and Eklund, 2010). Even if a unique definition of urban mining doesn't exist, this emerging research trend aims to consider cities as potential reserves of metals and minerals to such a point that they are called urban mines (Sun et al., 2016; Ciacci et al., 2017; Bonoli et al., 2018).

From the urban mining perspective, producing vast quantities of wastes may represent a flourishing market for recyclers operating in the field of Copper, Gold, Silvers, and Critical Raw Materials (CRMs). As pointed out by the EU Commission, this practice may strongly contribute to the proper management of dangerous substances (European Commission, 2018). Moreover, in contrast to open burning and illegal treatment, mainly adapted in emerging countries, the process of disassembly, isolate and purify materials represents an excellent alternative to the linear economy. These operations are based on multiple value capturing principles, with positive economic, social, and environmental implications. However, implementing a systemic reuse system from urban infrastructures and buildings is challenging (Brunner, 2011). A comprehensive information dataset on flows and stocks is essential. It assumes higher importance if we consider that more than 40 million metric tons of WEEE are generated every year (Forti et al., 2020). As reported in the Waste Hierarchy and highlighted by Cossu and Williams (2015), urban mining should be contextualized in circular thinking. The life cycle approach should be adopted to extract the highest value from materials and ensure a competitive market for secondary materials. It follows that WEEE and relative materials become a source of revenue to be perceived as an opportunity for the growth of sustainable high-tech industry, the promotion of green jobs, and the adoption of advanced labor skills (Krooks and Baas, 2013). It is imperative especially when it comes to CRMs, that are sensitive to the supply chain's reliability. Among various applications, materials recovery from lamps represents one of the significant opportunities for experimentation.

No studies have been carried out yet on the recovery of REEs from small fluorescent lights used in Liquid-Crystal-Display (LCD) backlights or from phosphors used in white Light-Emitting-Diodes (LEDs) (Buchert et al., 2012). This work represents a preliminary multi-criteria analysis aimed at assessing the feasibility of launching an urban mining project based on the valorization of REEs from fluorescent lamps. 


\section{THE VALUE OF RARE EARTH ELEMENTS IN CIRCULAR ECONOMY}

Rare Earth metals (and relative oxides) are widely used in EE applications. REEs are 17 elements, 15 of the Lantanoid series over than Scandium and Yttrium. REEs are categorized into "Heavy Rare Earths" and "Light Rare Earths." Lanthanum, Cerium, Praseodymium, Neodymium, Promethium, and Samarium are the Light Rare Earths while Yttrium, Europium, Gadolinium, Terbium, Dysprosium, Holmium, Erbium, Thulium, Ytterbium, and Lutetium can be considered Heavy Rare Earths (de Boer and Lammertsma, 2013). Despite the adjective "rare", which is mainly linked to the difficulties in the extraction process, REEs are widely present in the EEarth's crust. From a mineralogical point of view, REEs are considered "trace elements" because of their presence in some minerals that are not very abundant in common rocks (carbonates, oxides, phosphates, and halides). REEs are also characterized by a deficient concentrations in the reservoirs. They exist in a conglomerate form that implies complex and expensive extraction and separation processes. It follows that the economic exploitation of the deposits is profitable only in a few areas of the Earth, where the largest Rare Earths reserves are present, i.e. China, Brazil, Russia, India, Australia, Greenland, and the USA. Among them, China is the crucial player controlling more than $90 \%$ of the global market, thus achieving a substantial monopoly. The vital power of the Chinese EE industry on the global REEs market is strongly related to its business. Chinese-based companies have gained supremacy in the market since the 1980s thanks to their suddenness in reaching REEs growing demand through very low-price policy based on high volume supply and labor exploitation. This supremacy has never been jeopardized. Nowadays, all REEs' global reserves are estimated to be about $114 \mathrm{Mt}$, mainly located in China (Deboer and Lammertsma, 2013). China turns out to be the largest producer and exporter and consumer of Rare Earths, followed by USA and Japan.

To prevent possible future shortages without exceeding the extraction activity, EU countries, and specifically Italy, have to enhance a robust recycling activity, consisting mainly of WEEE proper management and valorization. In addition to self-sufficiency, recycling represents a valid option from an environmental point of view. However, many critical issues remain. The REEs processing is expensive, energy and resource-consuming: during the extraction and the mineral valorization phases, a large amount of water and chemicals is used, and at the same time, atmospheric releases are high and, vast amounts of solid waste and wastewater are generated. It has been estimated that the processing of a tonnage of Rare Earth metals involves the generation of about 2.000 tons of toxic waste. Furthermore, REEs are often associated with some radioactive materials, affecting the quality of the residual slags and emissions with risks for the ecosystems.

Despite the enormous environmental impact on the mining of REEs, the demand for REEs is growing. The industry is rapidly advancing with new and innovative electric devices and newly developed energy systems that increasingly need REEs' application on a large scale. In particular, Praseodymium, Neodymium and Dysprosium are widely applied in permanent magnets production (for wind turbines, electric cars, speakers, hard disks). Erbium, Holmium, and Gadolinium are commonly used in medical-surgical lasers. Terbium, Yttrium, and Europium are supplied for the lighting technology industry manufacture lamps and flat-screen luminophores. More generally, all REEs are used in a multitude of applications, including high-tech products, such as special steels and alloys, pigments, optical fiber and glass, rechargeable batteries, microwave devices, space and aircraft engines, components for satellites, catalysts for the petrochemical and polymer industry, catalytic converters, very high power lasers, superconductors, nuclear batteries, nuclear reactors, anticancer drugs, substances and sensors for Magnetic Resonance and Positron Emission Tomography diagnostics. They are also handled in electronic and IT components with high miniaturization, nanotechnologies, high-intensity lighting, solar cells, night vision devices.

The fluorescent lamp production can be considered the significant goods daily sold among the small electronic devices. As defined within the Directive 244/2009/EC (2009), fluorescent lamp means "a discharge lamp of the low-pressure Mercury type in which most of the light is emitted by one or several layers of phosphors excited by the ultraviolet radiation from the discharge". Fluorescent lamps are supplied either with or without integrated ballasts; Lanthanum, Terbium, Yttrium and Europium and their oxides are used as internal coating powders to filter the UV radiation generated by exciting the internal gas and resulting in a visible white light. In Figure 1 a typical fluorescent lamp and the lamps storage at the investigated plant.
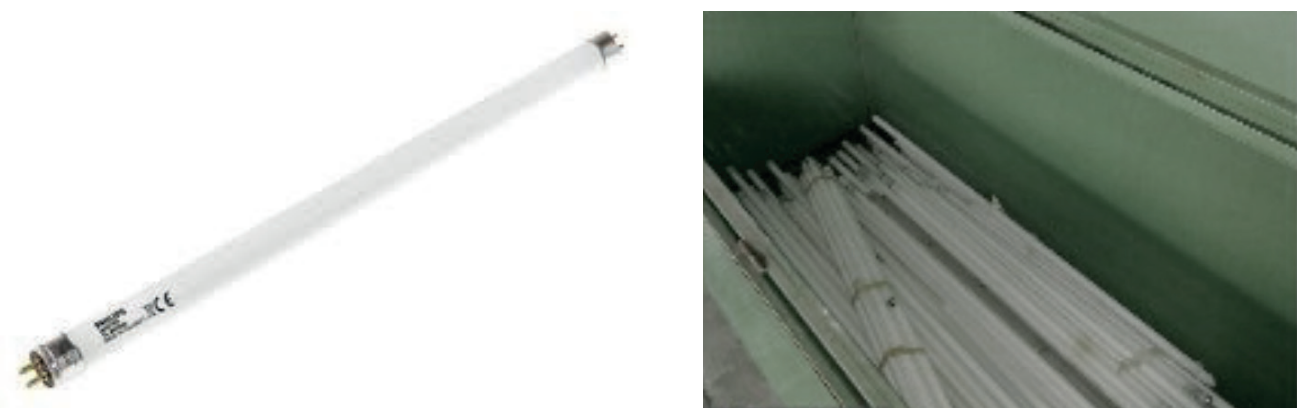

FIGURE 1: A common fluorescent lamp and storage of lamps at investigated plant. 
Fluorescent lamps were launched on the market at the end of the 1980s as an advantageous alternative to incandescent bulbs. The fluorescent lamps' benefits can be summarized in lower energy consumption, long life span, and superior light output. The demand robustly increased after the eco-design requirements established by the EU Directive 244/2009. The limited life span and the fast substitution have fostered a large volume of waste to be managed. Furthermore, because of some hazardous components, such as Mercury in tube light, a specific collection and treatment process is required. Therefore, the focus on this type of waste hasgrown over time due to the rising attention on environmental protection practices and the interest in recovering essential and strategic minerals, including REEs. This attention was also registered in the EU policy and decision-making process through the establishment of the Directive 2002/95/EC (the so-called RoHS 1 Directive) and the Directive 2011/65/EU (the so-called RoHS 2 Directive) that prohibited specific substances for EEEs marketed in the EU.

Fluorescent lamps can be tubular or compact. The socalled "neon tubes" can be linear or circular. They are identified with the following standard diameters: T12 (diameter $38 \mathrm{~mm}$, the old fluorescent tubes), T8 (diameter $26 \mathrm{~mm}$ ), the most used in indoor environments, and T5 $(16 \mathrm{~mm}$ diameter), the new generation of fluorescent lamps, with reduced dimensions and electronic power supply, hence excellent energy efficiency. Light intensity and color mainly depend on the internal coating of fluorescent powders which can be obtained by phosphorus trioxide (triphosphorous) and phosphorus pentoxide (pentaphosphorus). Because of their composition, outdated fluorescent lamps represent an actual and precious urban reserve of materials. It is possible to recover glass, metals, minerals and especially heavy and light REE. Three of the rare earths generally included in lamps (Europium, Terbium, Yttrium) are considered CRMs (Binnemans, 2014). The kind of recycling process depends on the type of minerals. Some authors (Kumar, 2016) suggest adopting a chemical treatment such as the acid dissolution for oxides (i.e for Yttrium recovery). Following this process, the phosphorous powders from fluorescent lamps are treated using a leaching process and an extraction process with solvent called solvent extraction. The most efficient process (Innocenzi, 2017) consists of a multistage liquid-liquid extraction with cross-currents between the aqueous solution and an organic extracting solution in acid conditions by adding an oxalic acid. Yttrium is recovered as Oxalate Hydrate with a purity of around $97,5 \%$. To avoid chemicals utilization, a new methodology for the recovery of Yttrium and Europium has been proposed (Van den Bogaert, 2015). The process is based on ultraviolet (UV) rays applied to aqueous solutions containing Europium and Yttrium in ionic form. UV light affects ions electrically, adding energy to the solution. As a result, a positive charge for the Europium ion is neutralized and if sulfate is added, Europium reacts with it, and the precipitate that is formed can be easily filtered, while Yttrium remains in the solution. The result is a $95 \%$ Europium extract and a remaining $98,5 \%$ Yttrium solution. The process results in greater efficiency than the liquid-liq- uid separation, with the additional benefit of preventing dangerous chemical by-products. Because of its larger economic value over all other elements recoverable from lamps, a particular attention deserves Terbium.

An experimental process suggests the possibility of extraction of REEs, as phosphates, especially aimed at maximizing the recovery of Terbium from fluorescent powders. Some dated studies (Merritt, 1990) suggest that RE phosphates, thermally pretreated in an alkaline solution, can be transformed into RE oxides. This process allows obtaining a lower acid concentration, with a hydrometallurgical solubilization treatment and the following segregation by using organic solvents. By identifying the optimal operating conditions (i.e temperature, solid concentration and reaction time of the leaching), the most effective extraction of rare earths can be obtained. In this case, the result was the separation of the initial solution into two mixtures, one with a high percentage of Yttrium (over $98 \%$ ), with slight traces of other REEs, the different mixture containing several REEs, including Terbium, which has exceeded $70 \%$ by weight.

In this case, the possibility to recover REEs from "EoL" fluorescent lamps', internal coating powders has been explored. The research activity has been carried on at fullscale level, involving an Italian company specialized in WEEE recycling. Fluorescent lamps have been collected, treated, and analyzed to examine REEs content and the potential to recycle residual powders that are actually disposed of in the landfill. The work specifically aims to recover Terbium, Europium, and Yttrium oxides.

\section{CASE STUDY: THE VALORIZATION OF TERBIUM, EUROPIUM AND YTTRIUM OXIDES FROM END-OF-LIFE FLUORESCENT LAMPS}

\subsection{Materials and method}

\subsubsection{Waste collection and characterization}

The EEs recycling industry typically consists of waste collection and transport, dismantling, size reduction, sorting, and separation. The metallic concentrates are further subjected to smelting and refining (Hageluken, 2005). Efficient collection schemes have been set up in Europe (Binnemans and Jones, 2014). Exhausted or discarded lamps are considered hazardous waste because they contain MercuryMercury and must be collected separately from other waste in specific bins. Through the WEEE collection and transport chain, the lamps reach DISMECO company. Here, a dedicated system for all constituents, consisting of containing materials, carries out a mechanical separation. According to the type of lamps and the economic life service time, REEs occur in various ratios; therefore, quantity and quality can widely vary from product to product. It follows that identifying the materials, and therefore, the characterization of the waste is a time-consuming work. In the present study, a waste characterization procedure has been set up to identify the waste status and give the appropriate EU waste code. This activity allows identifying the materials in lamps and preparing a preliminary analysis of the potential separation efficiency (\%), the recycling per- 
formance, and, finally, the percentage of waste destined to incineration or landfill.

To evaluate the separation and recovery efficiency, the following Equation (1) has been used per each material that is potentially valorizable:

- Recovery Efficiency $(\mathrm{RE})=\left(\mathrm{Wmi}_{\text {output }} / \mathrm{Wmi}_{\text {input }}\right) \star 100$

where:

$\mathrm{Wmi}_{\text {input }}=$ the weight of material (mi) in input $(\mathrm{kg})$

$\mathrm{Wi}_{\text {output }}=$ the weight of material (mi) in output $(\mathrm{kg})$

Simultaneously, the REE's complementary value, the Disposal Amount (DA, \%) represents the amount of waste (in \%) disposed of in an incinerator or landfill.

- Disposal Amount $(\mathrm{DA})=100-\mathrm{RE}$

\subsubsection{End-of-life lamps treatment}

The literature reports three different methods to treat fluorescent lamps:

- direct reuse of phosphorous mixture from lamps;

- recycling of the phosphor components through a physicochemical separation process;

- chemical methods to recover the REE content (Binnemans et al., 2013; Binnemans and Jones, 2014).

In this study, the latter approach has been used. Tube light lamps with external glass or a plastic protective tube must be removed before the mechanical processing. Other lamps (i.e. unusual formats, circular tubes, U-tubes, etc., or broken ones), require a pre-treatment process where additional waste, such as plastics, paper, or other packaging materials, have to be separated. Before mechanical treatment, lamps have to be dried as humidity hinders the functioning of the filters and decreases the system's capacity to separate the fluorescent powders from glass. A mechanical treatment system has been used for the present study, named CCS Unit (Compact Crush and Sieve Unit). It is composed of: a hammer mill, two shredders, three air-material separation towers, a magnetic separator, a glass-metal conveyor, a metal separator, a glass discharge conveyor, a cyclone filter, two filters self-cleaning dust, a pneumatic handling system, four carbon filters, a control panel (see Figure 1).

The fluorescent tubes are fed into the hammer mill (A) to be crushed. In a first separation tower (B), the coarser materials (glass and metals) are separated from the finest particles (dust) inside an air flux. Glass and metals are (C) divided employing a vibrating screen. After a secondary crushing (D) phase, materials are transported by an airflow to the second separation tower and discharged (E-F). Glass andmetals are sorted by the means of a magnetic separator (G). Metals are collected in a container, while glass is further crushed $(\mathrm{H})$ and conveyed to the third separation tower (I). Finally, the glass is sent into the rotating feeder $(\mathrm{K})$ and to the discharging conveyor $(\mathrm{L})$, and collected in "big bags".

Fluorescent powders, carried by the air stream, are separated from a cyclone (M) and two filters $(N)$ system where fine particles are captured and discharged into containers positioned under each filter. The air is treated in- side a carbon filter (0) to capture residual Mercury vapors. All materials are transported to the processing plant by using a pneumatic system. A first gravity separation stage segregates the finest and lightest particles (powders) that continue in the flow. Afterward, coarse and heavy elements (glass, ferrous and non ferrous metals, Bakelite, etc.), after a size reduction with a hammer mill, are separated at the second stage of the gravity separation. Later, in other crushing and separation settings, powders are collected in "big bags".

Fluorescent powders containing Mercury vapors, are purified in three stages constituted by:

- a cyclone, where most of the dust is collected in a container;

- a couple of bag filters, where a separation dust-air occurs and fine particles are captured and discharged into containers while air is purified from the dust;

- activated carbon filters retaining Mercury vapors and avoiding their emissions into the atmosphere. Lamps are separated into different fractions represented by glass, ferrous metals, non-ferrous metals, fluorescent powders.

\subsubsection{Preparation of the samples}

The preparation of the sample consists of a first grinding phase to obtain a fine powder. Then, the powder is homogeneously mixed with a binder (wax, $\mathrm{H}_{3} \mathrm{BO}_{3}$ ) and pressed at $100 \mathrm{kN}$ in $13 \mathrm{~mm}$ pellets or at $200 \mathrm{kN}$ in $40 \mathrm{~mm}$ pellets. Then it is put on a sample holder and inserted into the machinery where a crystal geometrically disperses the emitted radiation (fluorescence). In that way, the different energies, i.e. the spectrum's different lines, can be detected according to the dispersion angle.

In the present study, two samples corresponding to two different batches of collected materials have been investigated. The powders have been extracted from the lamps to carry out a preliminary size analysis. Both samples, weighting $135 \mathrm{~g}$, have been submitted to a particle size analysis performed by a common mechanical siever. It was chosen a column of six sieves, (according to technical Iso standards) having the following meshes dimensions: 500, 300, $212,150,106,75$ microns.

\subsubsection{Fluorescent powder analysis}

Existing methods for the recovery of the detected materials have been explored to evaluate the concentration of the REEs and the other main constituents. In this study, a Wavelength Dispersion X-Ray Fluorescence (WD XRF) instrumentation has been chosen. The. X-Ray Fluorescence (XRF) spectrophotometry is a non-destructive technique, which allows the identification of chemical elements in a sample on the basis of the $\mathrm{X}$-ray fluorescence radiation emitted by the atoms following a high-energy $X$ and gamma rays irradiation. In particular, in the Wavelength Dispersion XRF (WD XRF) technique, the emitted radiation is geometrically dispersed by a crystal. The different energies, i.e. the different spectrum lines, can be detected as a function of the dispersion angle. The WD XRF detects the different wavelengths of the radiation emitted by the material (excit- 


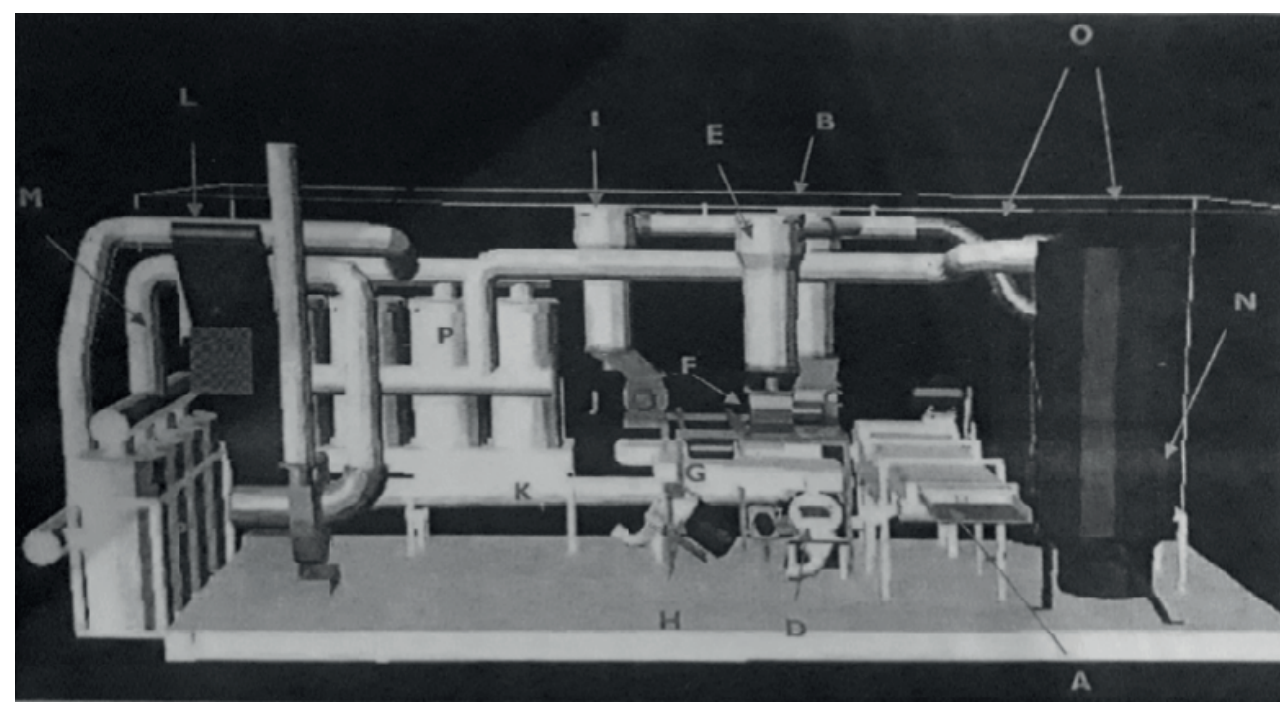

FIGURE 2: The CCS scheme.

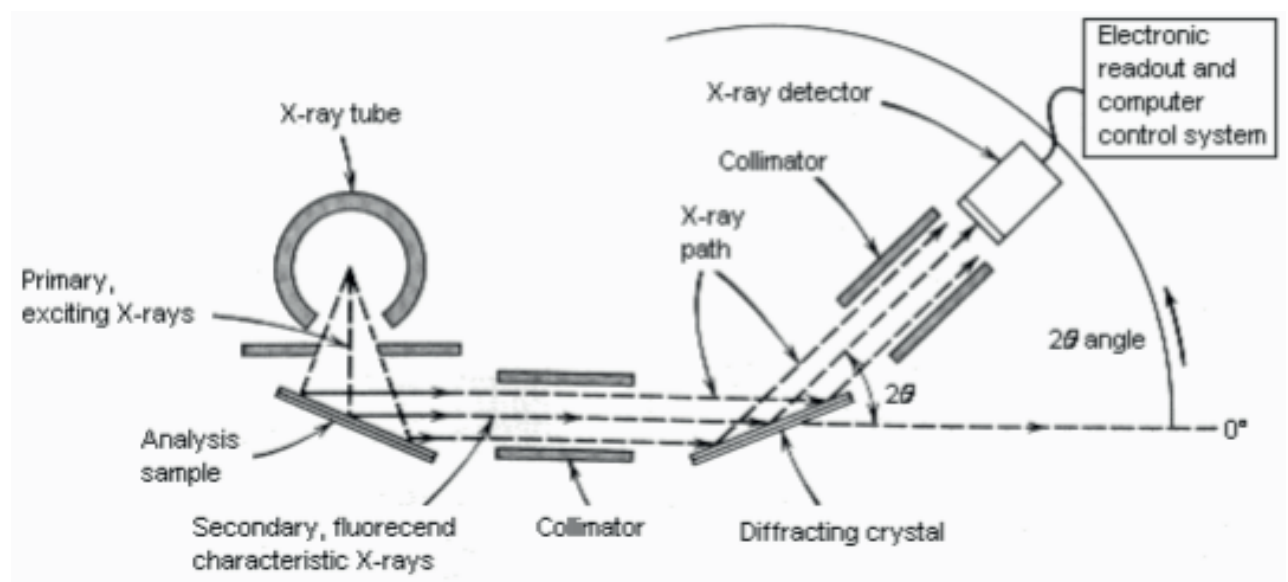

FIGURE 3: WD XRF instrumentation picture.

ed by the X-Rays) through the dispersion spectrum that it generates through a prismatic crystal. In Figure 2, the WD $\mathrm{XRF}$ instrumentation is shown.

The analysis was performed on two identical samples, weighting $7,60 \mathrm{~g}$. each, and considering three size intervals: $d<75 \mu \mathrm{m} ; \mathrm{d}=75 \div 150 \mu \mathrm{m} ; \mathrm{d}=150 \div 500 \mu \mathrm{m}$.

\section{RESULTS}

\subsection{Preliminary feasibility analysis}

Tests have been carried on defining the waste status and its classification according to the European waste code (see Table 1). Once the wastes have been codified, each material is weighted to measure the raw materials recovery efficiency. As shown in the table, the company carries out an almost total recovery for ferrous and non-ferrous metals, paper packaging and other lamps; a partial recovery occurs in cases of glass, plastics, and impure ferrous metals that will be sent to the energy recovery system. Fluorescent powders, on the other hand, are valorized through a physical-chemical treatment.
As described above, the following step is represented by the test analysis to identify and characterize the materials. Indeed, when an urban mining project is approached, the primary goal is to explore the potential extraction performance (Allwood et al., 2011). From an ordinary lamp, weighting about $200 \mathrm{~g}$, it is possible to exploit about 137 $\mathrm{g}$ of glass, $20 \mathrm{~g}$ of plastics, $13 \mathrm{~g}$ of metals, and $5 \mathrm{~g}$ of powders.

The results of the size analysis are reported in Table 2 , while Table 3 reports compound concentration at three different size ranges: $d<75 \mu \mathrm{m}, \mathrm{d}=75 \div 150 \mu \mathrm{m}$ and $\mathrm{d}=$ $150 \div 500 \mu \mathrm{m}$ for both samples. The particle size analysis was only functional to the subsequent detection of the REEs concentrations as a function of the samples' size. The data reveal that the types and amounts of elements found deviate slightly for the particle sizes $\mathrm{d}<75 \mu \mathrm{m}$ and $d=75 \div 150 \mu \mathrm{m}$. The sample with size $d=150 \div 500 \mu \mathrm{m}$ presents a high glass content, which increases proportionally with the elements' size.

In the second sampling, a greater atmospheric humid- 
TABLE 1: Test Recovery Efficiency.

\begin{tabular}{|c|c|c|c|c|c|}
\hline EU Waste Code & Description & Waste $(\mathrm{kg})$ & Mass Balance (\%) & $\begin{array}{l}\text { Materials Recovery } \\
\text { Efficiency (RE) (\%) }\end{array}$ & $\begin{array}{l}\text { Incineration Landfilling } \\
(\%)\end{array}$ \\
\hline 191212 & Powder & 10.537 & 5,30 & 0 & 100 \\
\hline 191202 & Ferrous Metals & 2.386 & 1,20 & 98 & 2 \\
\hline 191203 & Non Ferrous Metals & 3.579 & 1,80 & 100 & 0 \\
\hline 191205 & Glass & 136.078 & 68,45 & 20 & 80 \\
\hline 191204 & Plastics & 19.741 & 9,93 & 40 & 60 \\
\hline 160216 & $\begin{array}{l}\text { Ferrous and Non } \\
\text { Ferrous metals }\end{array}$ & 20.476 & 10,30 & 100 & 0 \\
\hline 150101 & Paper packaging & 4.970 & 2,50 & 100 & 0 \\
\hline \multirow[t]{2}{*}{$200121 * / 160214$} & Other lamps & 1.034 & 0,52 & 100 & 0 \\
\hline & Total & 198801 & 100 & & \\
\hline
\end{tabular}

TABLE 2: Size analysis results for the two tested samples.

\begin{tabular}{|c|c|c|}
\hline Sieve Size $(\mu \mathrm{m})$ & Sample 1 Cumulative Passing (\%) & Sample 2 Cumulative Passing (\%) \\
\hline 500 & 89,48 & 86,76 \\
\hline 300 & 72,75 & 71,67 \\
\hline 212 & 48,67 & 49,36 \\
\hline 150 & 24,50 & 24,36 \\
\hline 106 & 16,83 & 18,92 \\
\hline 75 & 8,51 & 9,57 \\
\hline 0 & 0 & 0 \\
\hline
\end{tabular}

ity resulted in an over-discharging of dust due to adhesion to the coarse glass from the towers This was proved by the analyzed fine dust in terms of high $\mathrm{SiO}_{2}$ percentage and a reduced presence of Rare Earth. It should be emphasized the result in terms of abatement of MercuryMercury which is always less than $0,02 \%$, demonstrating the high efficiency of the treatment.

Regarding the presence of REEs, Yttrium Oxide $\left(\mathrm{Y}_{2} \mathrm{O}_{3}\right)$, Lanthanum Oxide $\left(\mathrm{La}_{2} \mathrm{O}_{3}\right)$, Cerium Oxide $\left(\mathrm{CeO}_{2}\right)$, Europium Oxide $\left(\mathrm{Eu}_{2} \mathrm{O}_{3}\right)$, Therbium Oxide $\left(\mathrm{Tb}_{4} \mathrm{O}_{7}\right)$ and Gadolinium Oxide $\left(\mathrm{Gd}_{2} \mathrm{O}_{3}\right)$ have been found in both samples. The differences in \% can be explained because of the high glass content at the second sample mainly located at the more coarse particle size class (500-150 $\mu \mathrm{m})$.

The results show that the significant REEs percentage is contained in the finest powders. This trend is evident for all the oxides and both samples. The results relating to the most acceptable fraction $(<75 \mu \mathrm{m})$ remain substantially constant, providing helpful information for determining the dimensions in which to look for the REEs. However, significant amounts, although less, of REEs are also present at the other sizes. A first comparison between the two samples shows that the elements found and their quantities do not differ much, especially in sieving $<75 \mu \mathrm{m}$. At the $d=150 \div 500 \mu \mathrm{m}$, the second sample shows a higher glass content, probably due to humidity, making it more challenging to separate the glass from the dust. This analysis allows forecasting the yearly volume of lamps to treats and the amount of materials that can be potentially exploitable. By assuming about $21.000 \mathrm{~kg} /$ year of fluorescent lamp powders that can be treated at the plant, Table
4 shows the total amount of REEs that can be recovered yearly.

\subsection{Economic feasibility analysis}

Once the materials have been registered in a database and weighted, it is necessary to estimate the economic benefits and the maximum value extracted from lamps to assess the actual economic feasibility (Krook, 2010; Cossu and Williams, 2015). Based on the results carried out by the preliminary analysis, a market and cost-benefit evaluation have been performed. At first, the current price of REEs in the international market has been overviewed. Updated in December 2019, all data are reported as RMB (the Chinese currency Renminbi) per kilos, as summarized in Table 5. As Deboer and Lammertsma (2013) noted, the prices of REEs have changed dramatically in the last years, reaching fluctuations of up to 10 . After a peak registered in 2011-2012, the prices quickly decreased in the following years.

Considering the plant recovery rate and the volume of materials potentially treated every year (see Table 6), the revenue from this kind of urban mining exploitation can be estimated.

At the same time, costs should be addressed. To minimize initial investments, representing the highest economic output, the possibility of activating joint public/private collaboration mechanisms has to be explored.

\section{DISCUSSION}

To date, the recovery of REEs is still almost entirely unexplored at large-scale level since the techniques 
TABLE 3: Compound concentration for the two tested samples (REEs in bold).

\begin{tabular}{|c|c|c|c|c|c|c|}
\hline \multirow[t]{2}{*}{ Compound Name } & \multicolumn{3}{|c|}{ Sample 1} & \multicolumn{3}{|c|}{ Sample 2} \\
\hline & $\begin{array}{c}\mathbf{5 0 0 - 1 5 0 \mu \mathrm { m }} \\
\text { Concentration [\%] }\end{array}$ & $\begin{array}{c}150-75 \mu \mathrm{m} \\
\text { Concentration [\%] }\end{array}$ & $\begin{array}{l}\quad<75 \mu \mathrm{m} \\
\text { Concentration [\%] }\end{array}$ & $\begin{array}{c}\mathbf{5 0 0 - 1 5 0} \mu \mathrm{mm} \\
\text { Concentration [\%] }\end{array}$ & $\begin{array}{c}150-75 \mu \mathrm{m} \\
\text { Concentration [\%] }\end{array}$ & $\begin{array}{l}\quad<75 \mu \mathrm{m} \\
\text { Concentration [\%] }\end{array}$ \\
\hline $\mathrm{SiO}_{2}$ & 32,00 & 29,13 & 22,18 & 68,27 & 30,79 & 17,22 \\
\hline $\mathrm{Al}_{2} \mathrm{O}_{3}$ & 15,33 & 17,39 & 18,40 & 2,49 & 12,14 & 13,37 \\
\hline $\mathrm{CaO}$ & 14,87 & 14,75 & 16,79 & 6,56 & 18,57 & 22,61 \\
\hline $\mathrm{P}_{2} \mathrm{O}_{5}$ & 11,35 & 12,52 & 14,16 & 0,18 & 14,61 & 16,38 \\
\hline $\mathrm{Y}_{2} \mathrm{O}_{3}$ & 8,60 & 9,60 & 10,95 & 0,08 & 6,44 & 9,04 \\
\hline $\mathrm{Na}_{2} \mathrm{O}$ & 6,37 & 5,82 & 4,72 & 16,14 & 7,05 & 4,74 \\
\hline SrO & 1,77 & 2,05 & 2,90 & 0,08 & 0,43 & 0,67 \\
\hline $\mathrm{BaO}$ & 1,54 & 1,37 & 1,24 & 0,57 & 1,55 & 2,13 \\
\hline $\mathrm{CdO}$ & 1,32 & 1,29 & 1,21 & 0,68 & 1,01 & 1,61 \\
\hline $\mathrm{La}_{2} \mathrm{O}_{3}$ & 1,03 & 1,15 & 1,45 & - & 0,50 & 1,28 \\
\hline $\mathrm{CeO}_{2}$ & 1,02 & 1,17 & 1,44 & 0,28 & 0,64 & 1,42 \\
\hline $\mathrm{K}_{2} \mathrm{O}$ & 0,89 & 0,77 & 0,56 & 1,32 & 0,75 & 0.54 \\
\hline $\mathrm{Eu}_{2} \mathrm{O}_{3}$ & 0,71 & 0,83 & 0,99 & - & 0,45 & 0,73 \\
\hline $\mathrm{Tb}_{4} \mathrm{O}_{7}$ & 0,56 & 0,65 & 0,82 & - & 0,37 & 0,62 \\
\hline $\mathrm{Fe}_{2} \mathrm{O}_{3}$ & 0,42 & 0,47 & 0,58 & 0,17 & 0,40 & 0,52 \\
\hline $\mathrm{Gd}_{2} \mathrm{O}_{3}$ & 0,39 & 0,42 & 0,57 & - & 0,31 & 0,56 \\
\hline $\mathrm{PbO}$ & 0,38 & 0,33 & 0,21 & 0,31 & 0,58 & 0,24 \\
\hline $\mathrm{GeO}_{2}$ & 0,33 & 0,39 & 0,55 & 0,32 & 0,30 & 0,05 \\
\hline $\mathrm{SO}_{3}$ & 0,19 & 0,20 & 0,18 & 0,17 & 0,16 & 0,12 \\
\hline $\mathrm{MnO}$ & 0,19 & 0,20 & 0,27 & 0,01 & 0,27 & 0,47 \\
\hline $\mathrm{Cl}$ & 0,17 & 0,19 & 0,22 & 0,04 & 0,21 & 0,24 \\
\hline $\mathrm{NiO}$ & 0,16 & 0,18 & 0,24 & 0,15 & 0,08 & 0,15 \\
\hline $\mathrm{Sb}_{2} \mathrm{O}_{3}$ & 0,14 & 0,12 & 0,16 & 0,04 & 0,21 & 0,40 \\
\hline $\mathrm{TiO}_{2}$ & 0,07 & 0,07 & 0,07 & 0,06 & 0,08 & 0,06 \\
\hline $\mathrm{WO}_{3}$ & 0,07 & 0,07 & 0,12 & 0,08 & 0,06 & 0,09 \\
\hline $\mathrm{ZnO}$ & 0,05 & 0,05 & 0,08 & $<0.01$ & 0,05 & 0,09 \\
\hline $\mathrm{CuO}$ & 0,04 & 0,05 & 0,08 & 0,01 & 0,03 & 0,06 \\
\hline $\mathrm{SnO}_{2}$ & 0,04 & 0,03 & 0,07 & 0,03 & 0,03 & 0,03 \\
\hline $\mathrm{Cr}_{2} \mathrm{O}_{3}$ & 0,02 & 0,02 & 0,01 & $<0.01$ & 0,02 & 0,01 \\
\hline $\mathrm{HgO}$ & 0,02 & 0,01 & $<0.01$ & $<0.01$ & $<0.01$ & 0,02 \\
\hline $\mathrm{Bi}_{2} \mathrm{O}_{3}$ & 0,01 & 0,01 & 0,01 & $<0.01$ & $<0.01$ & $<0.01$ \\
\hline
\end{tabular}

TABLE 4: Potential yearly amount of REE $(\mathrm{kg})$.

\begin{tabular}{|c|c|c|c|c|c|c|c|c|}
\hline & \multicolumn{4}{|c|}{ Sample 1} & \multicolumn{4}{|c|}{ Sample 2} \\
\hline & $d=500-150 \mu \mathrm{m}$ & $d=150-75 \mu \mathrm{m}$ & $\mathrm{d}<75 \mu \mathrm{m}$ & Total & $d=500-150 \mu m$ & $d=150-75 \mu \mathrm{m}$ & $d<75 \mu \mathrm{m}$ & Total \\
\hline $\mathrm{Y}_{2} \mathrm{O}_{3}$ & 1806,0 & 2016,0 & 2299,5 & 6121,5 & 16,8 & 1352,4 & 1898,4 & 3267,6 \\
\hline $\mathrm{La}_{2} \mathrm{O}_{3}$ & 216,3 & 241,5 & 304,5 & 762,3 & - & 105,0 & 268,8 & 373,8 \\
\hline $\mathrm{CeO}_{2}$ & 214,2 & 245,7 & 302,4 & 762,3 & 58,8 & 134,4 & 298,2 & 491,4 \\
\hline $\mathrm{Eu}_{2} \mathrm{O}_{3}$ & 149,1 & 174,3 & 207,9 & 531,3 & - & 94,5 & 153,3 & 247,8 \\
\hline $\mathrm{Tb}_{4} \mathrm{O}_{7}$ & 117,6 & 136,5 & 174,3 & 428,4 & - & 77,7 & 130,2 & 207,9 \\
\hline $\mathrm{Gd}_{2} \mathrm{O}_{3}$ & 81,9 & 88,2 & 119,7 & 289,8 & - & 65,1 & 117,6 & 182,7 \\
\hline
\end{tabular}

mentioned have remained at the experimental stage. As demonstrated by the preliminary feasibility analysis, the chemical treatment here described cancan extract considerable amounts of REEs from powders disposed of in the landfill. The quantities of Rare Earths recoverable from fluorescent lamps, as the analysis results have proved, are interesting to support an effective recycling process.

At the same time, limits and critical issues already exist. A summary $f$ challenges are here listed:

- lack of product-centric approach;

- high costs for extraction processes; 
TABLE 5: Price of Rare Earth Oxides (Updated in December 2019).

\begin{tabular}{|c|c|c|}
\hline & Price $[\mathrm{RMB} / \mathrm{kg}]$ & Price $[€ / \mathrm{kg}]$ \\
\hline Lanthanum Oxide & 12,25 & 1,6 \\
\hline Cerium Oxide & 12,25 & 1,6 \\
\hline Europium Oxide & 215 & 28,0 \\
\hline Gadolinium Oxide & 160 & 21,0 \\
\hline Terbium Oxide & 3470 & 450,0 \\
\hline Yttrium Oxide & 20 & 2,6 \\
\hline
\end{tabular}

TABLE 6: Potential revenue from the REEs valorization)

\begin{tabular}{|c|c|c|c|}
\hline & $\begin{array}{c}\text { Total amount } \\
{[\mathrm{kg}]}\end{array}$ & $\begin{array}{c}\text { Revenue } \\
{[€ / \mathrm{kg}]}\end{array}$ & $\begin{array}{l}\text { Yearly reve- } \\
\text { nue [ } € / \text { year] }\end{array}$ \\
\hline Lanthanum Oxide & 762,3 & 1,6 & 1219,68 \\
\hline Cerium Oxide & 762,3 & 1,6 & 1219,68 \\
\hline Europium Oxide & 531,3 & 28 & 14876,4 \\
\hline Gadolinium Oxide & 289,8 & 21 & 6085,8 \\
\hline Terbium Oxide & 428,4 & 450 & 192780 \\
\hline Yttrium Oxide & 6121,5 & 2,6 & 15915,9 \\
\hline
\end{tabular}

- high price volatility;

- generation of toxic by-products from the chemical techniques adopted to extract materials;

- relative costs to dispose of the toxic by-products;

- critical cost-benefits outputs because of the higher treatment costs compared to the market price of REEs

- fragmentation and lack of harmonization in the collection and treatment of fluorescent lamps at EoL;

- lack of incentives promoting research on separation of Mercury from fluorescent powders, making the latter more environmentally compatible and treatable at lower costs.

\section{CONCLUSIONS}

Given their properties and field of application, REEs have become fundamentally crucial for all industries manufacturing electronics and high-tech technologies. The growing interest in low-energy and intelligent technologies will massively affect REEs' market in the next ten years. However, as highlighted by the EU Commission, the EE industry is at risk due to the limited availability of primary resources. This critical issue is of the highest urgency for EU countries that import REEs from China as the primary producer, exporter, and consumer worldwide. REEs extraction, as well as transportation, have a significant impact from an environmental point of view. Additional effects have been registered at the economic and social level since China, taking advantage of the lack of environmental controls and regulations in exploitation and mining, leads the market as a monopoly.

To counteract this situation and ensure the future REEs supply, EU countries, driven by policies and regulations, have started to develop techniques for the recovery of REEs.

According to the type of electronic devices, materials and relative amounts can widely vary. Simultaneously, the limited presence of these materials is complicating the extraction process at such a point to be inconvenient from the economic point of view. In the case of lamps, the REEs recovery is not well-developed to date. The essential technologies would require long timeframes to exploit a functional industrial scale and provide an adequate supply source.

In the short term, the search for alternative substances for the development of technological appliances has not led to the discovery of valid substitutes: only REEs can guarantee, where used, high EE efficiency with drastic and indispensable dimensional reduction of components and appliances.

In the long run, since REEs are still used in the new LED generation, recycling should be robustly explored to translate material value into economic revenue and so foster the circularity of these materials. At the same time, additional efforts should be made in hazardous materials management: Mercury and radioactive elements (such as Uranium and Thorium) represent a pervasive presence in EE applications. By subjecting as much of WEEE as possible to REEs recovery and recycling processes, hazardous substance dispersion should decrease, at least within a controlled industrial environment.

The increasing awareness of resource scarcity and climate pressures have led industrial stakeholders to adopt pro-active behaviors aimed at reducing impacts and externalities in the environment. The EE industry has started a demanding route to prevent the supply of CRMs by implementing circular strategies: from eco-design to service-based system and finally, material recovery. All these actions promote on the one hand, the life service extension and in the other the value maintenance of the materials. The complexity in isolating and separating REEs from EEEs at EoL is challenging because of the minimum content. In Italy, about 200 companies are authorized to treat and valorize materials included in the WEEE stream. Among them, DISMECO srl, works on the processing of light-emitting devices. The substitution of fluorescent lamps with LED lamps has caused a rapid increase in the disposal of this lighting technology. The high volume of these products has boosted the company to think about a material valorization process to recover REEs. The sampling activitysampling activity results have encouraged the creation of collaboration forms with lamp designers and manufacturers in ordersampling activity results, enabling the creation of potential collaboration forms with lamp designers and manufacturers to adopt a product-centric approach able to optimize EoL performance. The establishment of Rare Earths' recovery centers would significantly reduce the technical and technological issues. This could also be translated into a positive economic value: either in terms of potential sales income of the substances obtained or as a stimulus to experimenting with advanced technologies. Indeed, even if fluorescent lamps have been substituted by LED lamps, their presence will remain in the WEEE stream for the next twenty years. Their proper treatment will feed the supply chain for the new lights that, in a systemic approach, should integrate additional strategies such as eco-design, assembly-disassembly, and finally, remanufacturing.

Despite the quantitative availability of fluorescent powders, the results of the analyses carried out in the present 
study do not highlight any truly significant contents of rare metals, such as to motivate a targeted recovery investment. The empirical analysis reveals high cost for material extraction and lack of substantial revenue from the REEs purchase. In the absence or pending further research progress based on the sustainable extraction process (at lower costs, with less use of chemical reagents and less generation of toxic by-products), the only possible alternative would be the use of economy of scale by developing integrated recycling routes. To manage higher volume, more harmonization in the collection scheme is necessary. After that, it is essential to boost cooperation and collaborations among the experts of the sectors and increase public entities' participation. Now that the COVID-19 pandemic has forced the European Community and nations to review the state aid criteria completely thoroughly, a new historical phase could open. Consequently, it would be likely possible to re-evaluate the support for companies working in sectors whose continuity is indispensable for the community, such as those protecting the environment and generators of work and income.

Therefore, this study, starting from a particular theme, explored technical and operational problems directly influencing possible industrial opportunities. Moreover, it had the ambition to highlight issues in a broader context, from local to the national level, up to the global one, intending to spread activities that increasingly support the circular economy and urban mining perspective.

\section{ACKNOWLEDGMENTS}

The authors would thank Dott. Andrea Malara, for performing part of the study within his Master Degree thesis at the University of Bologna and DISMECO Srl ${ }^{\odot}$ - leader company working on the WEEE treatment and valorization that has supported the present analysis.

\section{REFERENCES}

Allwood, Julian \& Gutowski, Timothy \& Worrell, Ernst. (2011). Material efficiency: A white paper. Resources, Conservation and Recycling. 55. 362-381. 10.1016/j.resconrec.2010.11.002.

Baccini, Peter \& Brunner, Paul. (2012). Metabolism of the Anthroposphere: Analysis, evaluation, design (2nd edition). 10.7551/mitpress/8720.001.0001.

Baker, L. (2012). Metabolism of the Anthroposphere: Analysis, Evaluation, Design, second edition, by PeterBaccini and Paul H.Brunner. Cambridge, MA, USA: The MIT Press, 2012, 408 pp., ISBN 978-0262-01665-0, \$35.00, cloth. Journal of Industrial Ecology. https:// doi.org/10.1111/j.1530-9290.2012.00558.x

Beamon,B.M.(1999). Designingthegreensupplychain.Logistics Information Management. https://doi.org/10.1108/09576059910284159

Binnemans, K., Jones, P. T., Blanpain, B., Van Gerven, T., Yang, Y., Walton, A., \& Buchert, M. (2013). Recycling of rare earths: A critical review. Journal of Cleaner Production. https://doi.org/10.1016/j. jclepro.2012.12.037

Binnemans, K., \& Jones, P. T. (2014). Perspectives for the recovery of rare earths from end-of-life fluorescent lamps. Journal of Rare Earths. https://doi.org/10.1016/S1002-0721(14)60051-X

BIO by Deloitte (2015) Study on Data for a Raw Material System Analysis: Roadmap and Test of the Fully Operational MSA for Raw Materials. Prepared for the European Commission, DG GROW. Available online: https://ec.europa.eu/assets/jrc/msa/images/ msa_final_report.pdf

Bonoli, A., Dolci, N., Foschi, E., Lalli, F., Prandtraller, D., Zanni, S. (2018). End Of Service Scenario For Universities' Informatic Equipment: Recovery And Repair As Educational And Research Tool For Circular Economy And Urban Mining. Detritus Journal.
Brunner, P. H. (2011). Urban mining a contribution to reindustrializing the city. Journal of Industrial Ecology. https://doi.org/10.1111/ j.1530-9290.2011.00345.x

Ciacci, L.; Vassura, I.; Passarini, F. Urban Mines of Copper: Size and Potential for Recycling in the EU. Resources 2017, 6,

Clarke, C., Williams, I. D., \& Turner, D. A. (2019). Evaluating the carbon footprint of WEEE management in the UK. Resources, Conservation and Recycling. https://doi.org/10.1016/j.resconrec.2018.10.003

Cossu, R., \& Williams, I. D. (2015). Urban mining: Concepts, terminology, challenges. Waste Management. https://doi.org/10.1016/j. wasman.2015.09.040

Deboer, M. A., \& Lammertsma, K. (2013). Scarcity of rare earth elements. ChemSusChem. https://doi.org/10.1002/cssc.201200794

European Commission (2012). Directive 2012/19/EU of the European Parliament and of the Council of 4 July 2012 on waste electrical and electronic equipment (WEEE). Available online: https://eur-lex. europa.eu/legal-content/EN/TXT/?uri=celex\%3A32012L0019.

European Commission (2016). Raw materials scoreboard. European innovation partnership on raw materials. Available online: https:// op.europa.eu/it/publication-detail/-/publication/1ee65e21-9ac4-1 1e6-868c-01aa75ed71a1

European Commission (2018). Report on Critical Raw Materials and the Circular Economy. Available online: https://ec.europa.eu/commission/ publications/report-critical-raw-materials-and-circular-economy_en

European Commission (2018b). DIRECTIVE (EU) 2018/849 OF THE EUROPEAN PARLIAMENT AND OF THE COUNCIL of 30 May 2018 amending Directives 2000/53/EC on end-of-life vehicles, 2006/66/ EC on batteries and accumulators and waste batteries and accumulators, and 2012/19/EU on waste electrical and electronic equipment. Available online: https://eur-lex.europa.eu/legal-content/EN/TXT/PDF/?uri=CELEX:32018L0849\&rid=4.

European Parliament and of the Council, 2015. Communication From The Commission To The European Parliament, The Council, The European Economic And Social Committee And The Committee Of The Regions. Closing the loop - An EU action plan for the Circular Economy. Available online: https://eur-lex.europa.eu/legal-content/EN/TXT/?uri=CELEX:52015DC0614

Fellner, Johann \& Lederer, Jakob \& Scharff, Christoph \& Laner, David. (2017). Present Potentials and Limitations of a Circular Economy with Respect to Primary Raw Material Demand: Present Potentials and Limitations of a Circular Economy. Journal of Industrial Ecology. 21. 10.1111/jiec.12582.

Forti V., Baldé C.P., Kuehr R., Bel G. The Global E-waste Monitor 2020: Quantities, flows and the circular economy potential. (2020) United Nations University (UNU)/United Nations Institute for Training and Research (UNITAR) - co-hosted SCYCLE Program, International Telecommunication Union (ITU) \& International Solid Waste Association (ISWA), Bonn/Geneva/Rotterdam.

Hagelüken, C. (2005). Recycling of electronic scrap at Umicore's integrated metals smelter and refinery. In Proceedings - European Metallurgical Conference, EMC 2005.

Ibanescu, D., Cailean (Gavrilescu), D., Teodosiu, C., \& Fiore, S. (2018). Assessment of the waste electrical and electronic equipment management systems profile and sustainability in developed and developing European Union countries. Waste Management. https://doi.org/10.1016/j.wasman.2017.12.022.

Innocenzi V., I. De Michelis I.,, Ferella F., Vegliò F.. (2017) Secondary yttrium from spent fluorescent lamps: Recovery by leaching and solvent extraction, 2017International Journal of Mineral Processing 168. DOI: 10.1016/j.minpro.2017.09.017

Krook, J., \& Baas, L. (2013). Getting serious about mining the technosphere: A review of recent landfill mining and urban mining research. Journal of Cleaner Production. https://doi.org/10.1016/j. jclepro.2013.04.043

Krook, J., \& Eklund, M. (2010). Urban mining-Prospecting for metals in the invisible city. ... \& Learning for ...

Kumar M., Panda R., Kumar J., (2016) Review on hydrometallurgical recovery of rare earth metals, Hydrometallurgy 161, Pages 77-101, Amsterdam, Elsevier, October 2016;

Li, J.; Zeng, X.; Chen, M.; Ogunseitan, O. A.; Stevels (2015). A. Control-Alt-Delete: Rebooting Solutions for the E-waste Problem. Environ. Sci.Technol. 49 (12), 7095-7108

Lieder, M., Asif, F. M. A., Rashid, A., Mihelič, A., \& Kotnik, S. (2017). Towards circular economy implementation in manufacturing systems using a multi-method simulation approach to link design and business strategy. International Journal of Advanced Manufacturing Technology. https://doi.org/10.1007/s00170-017-0610-9 
Merritt R.R. (1990), High temperature methods for processing monazite: I. Reaction with calcium chloride and calcium carbonate Journal of the Less Common Metals, Vol. 166, Issue 2, Pages $197-$ 210, Amsterdam, Elsevier, 1 November 1990;

Oladele, A., Ogunseitan, Julie, M., Schoenung, Jean-Daniel M., Saphores, Andrew A., Shapiro (2009). The Electronics Revolution: From E-Wonderland to E-Wasteland. Science 2009, 326 (5953), 670-671.

Price, J. L., \& Joseph, J. B. (2000). Demand management - a basis for waste policy: A critical review of the applicability of the waste hierarchy in terms of achieving sustainable waste management. Sustainable Development. https://doi.org/10.1002/(SICI)10991719(200005)8:2<96::AID-SD133>3.0.C0;2-J

Riesener, M., Dolle, C., Mattern, C., \& Kres, J. (2019). Circular economy: Challenges and potentials for the manufacturing industry by digital transformation. In 2019 IEEE International Symposium on Innovation and Entrepreneurship, TEMS-ISIE 2019. https://doi. org/10.1109/TEMS-ISIE46312.2019.9074421
Sun, Z., Xiao, Y., Agterhuis, H., Sietsma, J., \& Yang, Y. (2016). Recycling of metals from urban mines - A strategic evaluation. Journal of Cleaner Production. https://doi.org/10.1016/j.jclepro.2015.10.116

UNEP (2011). Recycling rate of metals. A status report of the Working Group ON THE Global Metal Flows to the International Resource Panel. Available online: file:///C:/Users/utente/Downloads/metals_status_report_full_report_english.pdf

Van De Bogaert (2015). Separating rare earth metals with UV light. phys.org/news/2015-05-rare-earth-metals-uv.html

Wong, S. K. S. (2012). The influence of green product competitiveness on the success of green product innovation: Empirical evidence from the Chinese electrical and electronics industry. European Journal of Innovation Management. https://doi. org/10.1108/14601061211272385

Zorpas, A. A. (2016). Sustainable waste management through end-ofwaste criteria development. Environmental Science and Pollution Research. https://doi.org/10.1007/s11356-015-5990-5 